Article

\title{
Ecotopic Expression of the Antimicrobial Peptide DmAMP1W Improves Resistance of Transgenic Wheat to Two Diseases: Sharp Eyespot and Common Root Rot
}

\author{
Qiang Su, Ke Wang and Zengyan Zhang * \\ The National Key Facility for Crop Gene Resources and Genetic Improvement, Institute of Crop Sciences, \\ Chinese Academy of Agricultural Sciences, Beijing 100081, China; suqiangcaas@163.com (Q.S.); \\ wangke03@caas.cn (K.W.) \\ * Correspondence: zhangzengyan@caas.cn; Tel.: +86-010-82108781
}

Received: 26 December 2019; Accepted: 16 January 2020; Published: 18 January 2020

\begin{abstract}
Wheat (Triticum aestivum L.) is an important staple crop. Sharp eyespot and common root rot are destructive diseases of wheat. Antimicrobial peptides (AMPs) are small peptides with broad-spectrum antimicrobial activity. In this study, we synthesized the DIAMP1W gene, encoding Dahlia merckii DmAMP1, and investigated the antifungal role of DmAMP1W in vitro and in transgenic wheat. Protein electrophoresis analysis and in vitro inhibition results demonstrated that the synthesized DmAMP1W correctly translated to the expected peptide DmAMP1W, and the purified peptide inhibited growths of the fungi Rhizoctonia cerealis and Bipolaris sorokiniana, the pathogenic causes of wheat sharp eyespot and common root rot. DmAMP1W was introduced into a wheat variety Zhoumai18 via Agrobacterium-mediated transformation. The molecular characteristics indicated that DmAMP1W could be heritable and expressed in five transgenic wheat lines in $\mathrm{T}_{1}-\mathrm{T}_{2}$ generations. Average sharp eyespot infection types of these five DmAMP1W transgenic wheat lines in $\mathrm{T}_{1}-\mathrm{T}_{2}$ generations decreased $0.69-1.54$ and $0.40-0.82$ compared with non-transformed Zhoumai18, respectively. Average common root rot infection types of these transgenic lines and non-transformed Zhoumai18 were 1.23-1.48 and 2.27, respectively. These results indicated that DmAMP1W-expressing transgenic wheat lines displayed enhanced-resistance to both sharp eyespot and common root rot. This study provides new broad-spectrum antifungal resources for wheat breeding.
\end{abstract}

Keywords: antimicrobial peptides; DmAMP1W; fungal resistance; Rhizoctonia cerealis; wheat

\section{Introduction}

Bread wheat (Triticum aestivum L.) is an important food crop, feeding $\approx 35 \%$ of the world's population [1]. Sharp eyespot is one of the most serious diseases for wheat production in different regions around the world [2]. Since late 1990s, sharp eyespot has seriously endangered wheat production in China, resulting in 10\%-30\% yield losses of wheat [3,4]. Rhizoctonia cerealis, a necrotrophic fungus, is the major pathogen of sharp eyespot in China. In nature, $R$. cerealis reproduces asexually and exists primarily as vegetative mycelium and/or sclerotia [5]. It can infect the roots and basal stems at any time during the wheat growing season, and in turn can devastate the transport of tissues in stems of wheat and obstruct transportation of nutrition substances $[3,6]$. Common root rot, caused by the soil-borne fungus Bipolaris sorokiniana, is another important disease of wheat [7]. B. sorokiniana mainly infects the roots and stem bases of wheat plants. Besides, some B. sorokiniana strains also can cause spot blotch, leaf spot disease, seedling blight, head blight and black point in wheat and barley [8,9]. Breeding resistant wheat cultivars are a friendly-environmental approach to protect wheat from fungal 
diseases. However, it is difficult to breed wheat varieties with resistance to sharp eyespot and common root rot by using traditional method, since no effective resistance accessions are available. Introducing alien genes conferring disease resistance by genetic transformation is an efficient alternative.

To defend against pathogens, plants can produce antimicrobial peptides (AMPs), which have an effect on growth inhibition against microorganisms [10-12]. Plant AMPs are structurally small, positively charged and cysteine-rich. AMPs are involved in various antifungal activities in vitro [10,13-15]. Some AMPs can directly affect cell membranes of fungi and change their structure, thereby inhibiting growth of the fungi [16-18]. For instance, Rs-AFP1, Rs-AFP2 and Rs-AFP3/4, isolated from seeds of Raphanus sativus, are the most in-depth-studied antimicrobial peptides in plant disease resistance [19-21]. Some studies have shown that Rs-AFP2 can resist to a variety of fungal diseases, such as rice sheath blight, rice blast, wheat sharp eyespot and fusarium head blight [13,20]. Similarly, Br-AMP1 (Brassica rapa) [22], Psd1 (Pisum sativum) [23], VrD1 (Vigna radiata) and MtDef2 (Medicago trunculata) [24] are seed specific AMPs, which can inhibit growth of several fungal pathogens. DmAMP1 was isolated from the seeds of Dhalia merckii and was reported to inhibit many fungal pathogens [25-28]. Bioassay showed that the DmAMP1 peptide extracted from leaves of transgenic papaya inhibited growth of Phytophthora palmivora in vitro; thus, ecotopic expression of DmAMP1 enhanced resistance to this fungal disease in the transgenic papaya [25]. Jha et al. indicated that ecotopic expression of DmAMP1 in transgenic rice could significantly enhance resistance to blast and rice sheath blight diseases. They demonstrated that $D m A M P 1$ was expressed independently in the transgenic rice lines and was not associated with rice $P R$-1 $a$ gene [26]. With the development of gene synthesis technology, synthetic peptide genes have been more and more used to defend against various fungal and bacterial pathogens [29]. Expression of the synthetic antimicrobial peptide D4E1 improved resistance of transgenic cotton plants to black root rot, because growths of the pathogenic fungi Fusarium verticillioides and Verticillium dahlia were inhibited by the protein isolated from D4E1 transgenic plants in vitro [30]. NaD1 (from Nicotiana alata) exhibited antifungal activity against $F$. vasinfectum and $V$. dahlia [31]. Ace-AMP1 could effectively enhance resistance against rice blast, sheath blight and bacterial leaf blight in vivo and in vitro, respectively [32]. In addition, Ace-AMP1 could increase resistance to fungal diseases powdery mildew and take-all in transgenic wheat plants $[33,34]$. However, defense function of DmAMP1 is poorly understood in wheat.

In this report, we aimed to study the inhibition activity of DmAMP1W against wheat disease pathogenic fungi in vitro and in transgenic wheat. The current results indicated that DmAMP1W peptide encoded by the synthesized DmAMP1W inhibited against growths of $R$. cerealis and B. sorokiniana, and DmAMP1W-expressing transgenic wheat plants displayed enhanced resistance to both fungal pathogens.

\section{Results}

\subsection{Heterogonous Expression and Purification of D $M A M P 1 W$}

The open-reading-frame sequence (ORF) of DmAMP1W was artificially synthesized according to wheat favor codons. It was predicted to encode the DmAMP1 amino acid sequence. The protein sequence analysis showed that the DmAMP1W peptide consists of 84 amino acid (AA) residues, with a molecular weight of $9.26 \mathrm{KD}$ and theoretical isoelectric point (pI) 7.68. SignalP4.0 and NCBI blastp showed that the DmAMP1W protein contained a signal peptide (locating number 1-28 AA residues) and a Knot1 domain (at 30 to 78 AA) harboring eight cysteines (Supplemental Figure S1). The DmAMP1W mature peptide was identical to that of DmAMP1 [35] (Supplementary Figure S2).

The ORF of DmAMP1W was sub-cloned and fused with the MBP tag in the prokaryotic expression vector PMAL-C5X (Figure 1A). The malE-DmAMP1W, where malE encodes the MBP tag, was predicted to encode the recombinant protein MBP-DmAMP1W. In order to obtain more amounts of MBP-DmAMP1W soluble fusion protein, we optimized the expression conditions. We established the optimum cultivation and induction conditions, when the culture cell density was OD600 $=0.6$, the culture was induced 
by the addition of $0.1 \mathrm{mM}$ isopropyl- $\beta$-D-thiogalactopyranoside (IPTG) under $28^{\circ} \mathrm{C}$ and for $\approx 12 \mathrm{~h}$ at $180 \mathrm{rpm}$. Sodium dodecyl sulphate-polyacrylamide gel electrophoresis (SDS-PAGE, 12\%) analysis showed that a clear expression protein band was found and should be MBP-DmAMP1W (Figure 1B). The MBP and MBP-DmAMP1W proteins were purified using Amylose Resin and were eluted by the MBP elution buffer, respectively. When these two solubilized proteins were monitored by gel electrophoresis, the sizes of the proteins were consistent with theoretical molecular masses of MBP and MBP-DmAMP1W (Figure 1C). MBP and MBP-DmAMP1W proteins were dissolved in MBP elution buffer $(0.04 \%$ maltose solution) to final concentration of $65 \mu \mathrm{g} / \mathrm{mL}$.

A

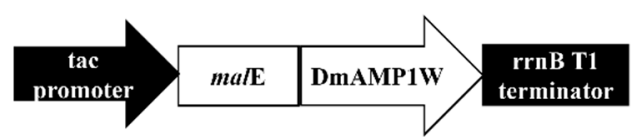

B

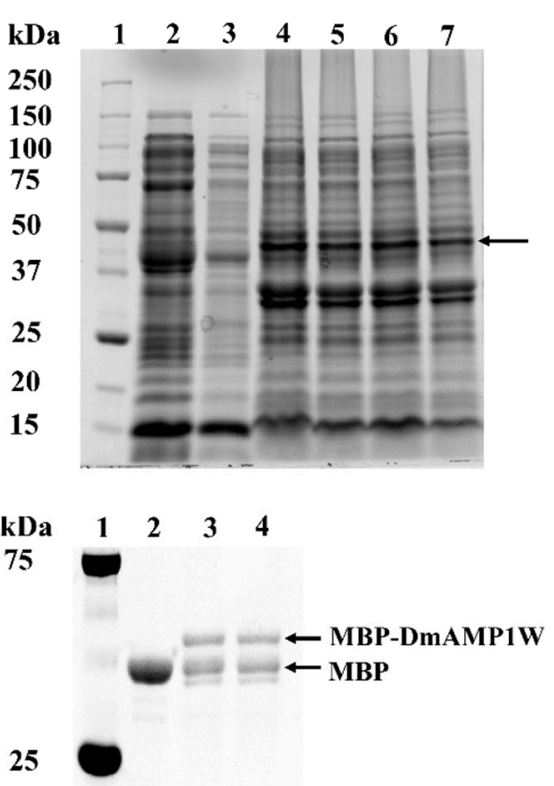

Figure 1. Expression and purification of MBP-DmAMP1W. (A) Construction of pMAL-C5X-DmAMP1W prokaryotic expression vector. In Escherichia coli, malE-DmAMP1W was predicted to encode the recombinant protein MBP-DmAMP1W. (B) SDS-PAGE (12\%) analysis of MBP and MBP-DmAMP1W fusion protein. Lane 1, protein marker. Lane 2 and 3, the supernatant of cell lysate of pMAL-C5X DE3. Lanes 4-7, the supernatant of cell lysate of pMAL-C5X-DmAMP1W DE3. The black arrow represents the target protein. (C) SDS-PAGE analysis of the purified MBP and MBP-DmAMP1W fusion protein. Lane 1, protein marker. Lane 2, purified MBP tag protein. Lane 3 and 4, purified MBP-DmAMP1W fusion protein.

\subsection{DmAMP1W In Vitro Inhibits Growth of R. cerealis and B. sorokiniana}

To examine inhibiting activity of the DmAMP1W against growths of fungal pathogens of wheat sharp eyespot and common root rot, $65 \mu \mathrm{g} / \mathrm{mL}$ MBP and $65 \mu \mathrm{g} / \mathrm{mL}$ MBP-DmAMP1W were injected into the small pores of PDA mediums, respectively, and then $R$. cerealis and B. sorokiniana were inoculated onto the PDA mediums. All treatments were performed three times. The results indicated that mycelium growths of $R$. cerealis and B. sorokiniana in PDA mediums injected with MBP-DmAMP1W were obviously inhibited compared with the MBP-treated (control) parts (Figure 2). Interestingly, three days after inoculation, when the mycelium filled up MBP-treated PDA medium, the areas treated with MBP-DmAMP1W formed inhibition zones, and they lasted for $10 \mathrm{~d}$. 


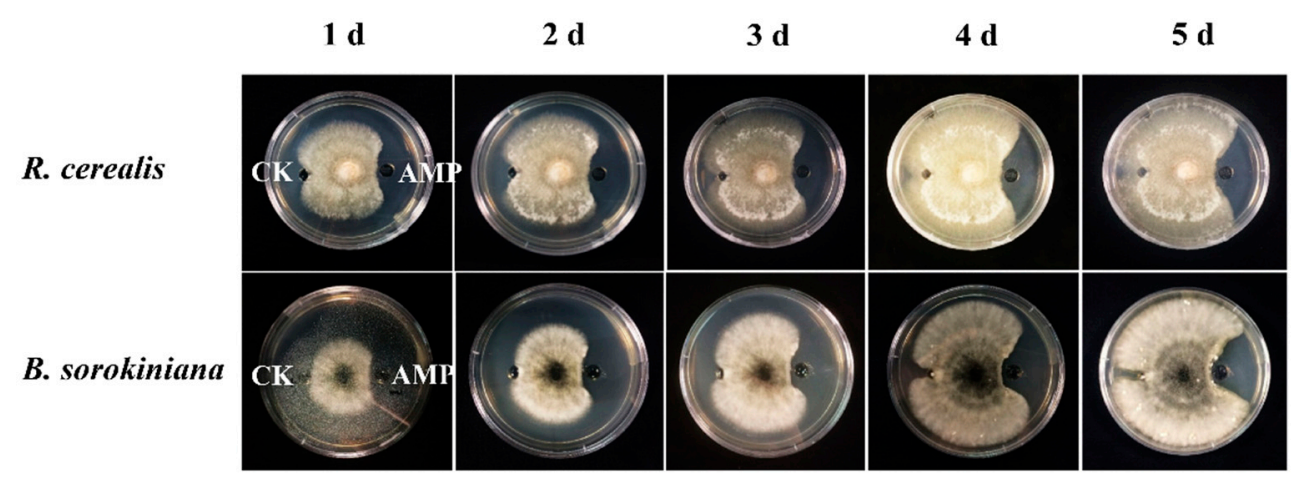

Figure 2. Inhibitory activity of DmAMP1W against Rhizoctonia cerealis and Bipolaris sorokiniana. The growth of pathogenic fungi mycelium within five days after inoculation was exhibited from left to right. The fungal mycelia on plates were treated by $65 \mu \mathrm{g} / \mathrm{mL}$ MBP and $65 \mu \mathrm{g} / \mathrm{mL}$ MBP-DmAMP1W, respectively. $\mathrm{CK}$ and $\mathrm{AMP}$ on the mediums represent MBP and MBP-DmAMP1W treatments, respectively. These assays were conducted three times with similar results.

\subsection{Generation and Molecular Characterization of DmAMP1W Transgenic Wheat}

The monocot expression vector pWMB122-DmAMP1W (Figure 3A), encoding DmAMP1W-His fusion protein, was used to transform a high-yield wheat cv. Zhouami18 via Agrobacterium-mediated method. As expected, transgenic wheat plants were generated. Using PCR by the primers specific to the transformation construct, an amplified product with 267-bp length was present in all the positive plants and the positive control vector (pWMB122-DmAMP1W), but absent in the negative plants and non-transformed (WT) recipient Zhouami18 (Figure 3B). Simi-quantitative RT-PCR results indicated that the fragment specific to the DMAMP1W transcript was observed in both five positive transgenic wheat lines and pWMB122-DmAMP1W plasmid, but absent in WT Zhouami18. Further RT-qPCR analysis indicated that $D m A M P 1 W$ could be expressed in all the tested organs (spike, leaf, leaf sheath and stem) of the transgenic wheat plants, and the highest expression occurred in the stems (Figure 3D). Western blot (immunoblot) analysis exhibited that DmAMP1W-His fusion protein was expressed in these five transgenic wheat lines but not in WT Zhoumai18 (Figure 3E).

\subsection{DmAMP1W Expression Improves Resistance of Transgenic Wheat to Sharp Eyespot and Common Root Rot}

To investigate defense ability of $D m A M P 1 W$ in wheat against $R$. cerealis, we assessed resistance of DmAMP1W transgenic wheat plants in $\mathrm{T}_{1}-\mathrm{T}_{2}$ generations to sharp eyespot after the pathogen inoculation. The assessment results indicated that these five DmAMP1W transgenic wheat lines displayed significantly enhanced-resistance to R. cerealis compared to WT Zhoumai18. According to the assessment results of $T_{1}$ resistance to sharp eyespot, five lines with heightened-resistance, namely DA1, DA2, DA3, DA4 and DA5, were selected to further assess in $T_{2}$ generation. Average infection types (Its) of these five transgenic wheat lines (DA1, DA2, DA3, DA4 and DA5) in $\mathrm{T}_{1}-\mathrm{T}_{2}$ generations were 1.37-2.22 and 2.30-2.72, while those of WT Zhoumai18 plants were 2.91 and 3.12. The average ITs of these five transgenic wheat lines decreased $0.69-1.54$ and $0.40-0.82$ compared with WT Zhoumai18, respectively (Table 1). Meanwhile, the disease severities and indices of these DmAMP1W transgenic wheat plants were significantly less and decreased than those of WT Zhoumai18 plants (Figure 4A, Table 1). The above results proved that expression of $D m A M P 1 W$ significantly increased resistance of the transgenic wheat plants to sharp eyespot. 
A

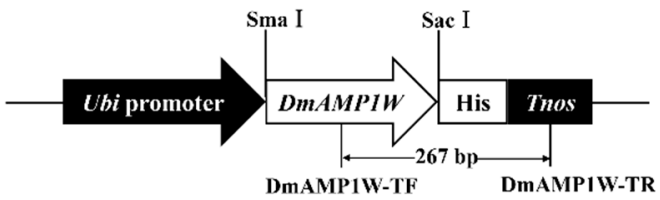

B

WT P DA1 DA2 DA3 DA4 DA5

$\mathbf{T}_{1}$

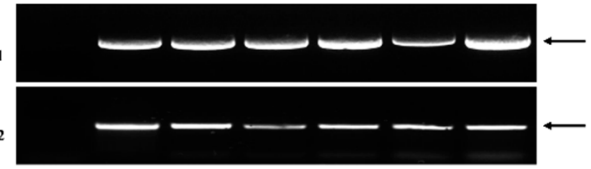

C

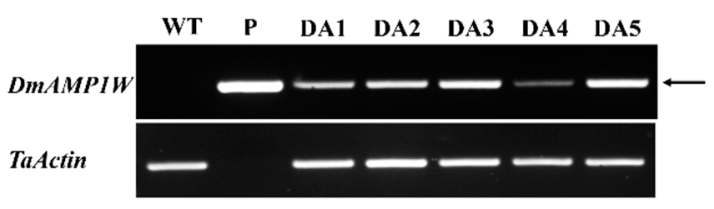

D

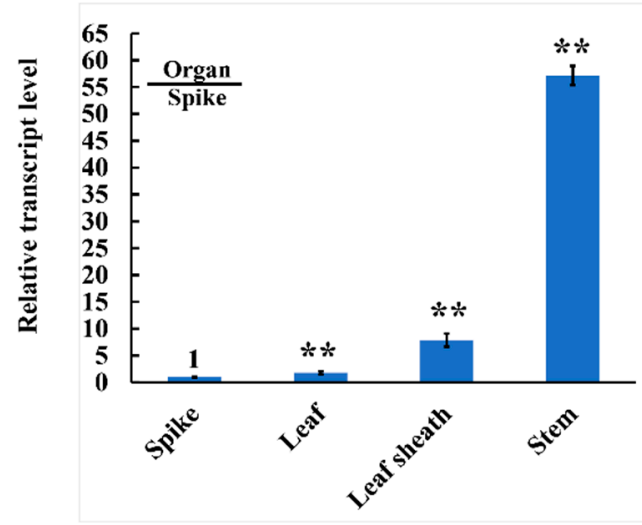

$\mathbf{E}$

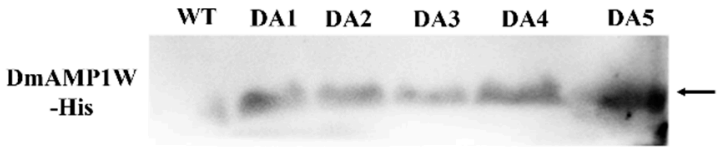

Figure 3. Plant expression vector and molecular characterization in DmAMP1W transgenic wheat plants. (A) Plant expression vector pWMB122:DmAMP1W-His. Tnos, $3^{\prime}$ untranslated terminator region of the Agrobacterium tumefaciens nopaline synthase gene. The arrow indicates the fragment amplified in the PCR detection. (B) PCR patterns of DmAMP1W in $\mathrm{T}_{1}-\mathrm{T}_{2}$ transgenic plants. WT indicates the non-transformed Zhoumai18. P represents pWMB122:DmAMP1W-His vector as positive control. DA1, DA2, DA3, DA4 and DA5 represent DmAMP1W transgenic wheat lines. (C) Semi-quantitative RT-PCR assays of DmAMP1W transcript in transgenic wheat. The amplification of semi-quantitative RT-PCR took 27 cycles. WT indicates the non-transformed Zhoumai18. P represents pWMB122:DmAMP1W-His vector as positive control. DA1, DA2, DA3, DA4 and DA5 represent DmAMP1W transgenic wheat lines. (D) qRT-PCR analysis of the organ expression pattern of DmAMP1W in transgenic wheat lines at $30 \mathrm{~d}$ post $R$. cerealis inoculation. Total RNA was extracted from spike, leaf, leaf sheath and stem organs of the five transgenic wheat lines. Each sample of three technique replications was averaged and statistically treated (Student's $t$-test; ${ }^{* *} p<0.01$ ). Error bars represents standard errors. (E) DmAMP1W-His fusion protein in transgenic plants in $\mathrm{T}_{2}$ and recipient Zhoumai18 was monitored by immunoblot analysis with the polyclonal anti-His antibody. 
Table 1. Responses of DmAMP1W transgenic wheat lines to sharp eyespot.

\begin{tabular}{ccccc}
\hline \multirow{2}{*}{ Lines } & \multicolumn{2}{c}{$\mathrm{T}_{\mathbf{1}}$} & \multicolumn{2}{c}{$\mathbf{T}_{\mathbf{2}}$} \\
\cline { 2 - 5 } & IT & DI & IT & DI \\
\hline DA1 & $2.17^{* *}$ & $43.41^{* *}$ & $2.50^{* *}$ & $50.00^{* *}$ \\
DA2 & $1.81^{* *}$ & $36.27^{* *}$ & $2.57^{* *}$ & $51.40^{* *}$ \\
DA3 & $2.22^{*}$ & $44.36^{*}$ & $2.72^{*}$ & $54.40^{*}$ \\
DA4 & $1.72^{* *}$ & $34.47^{* *}$ & $2.30^{* *}$ & $46.00^{* *}$ \\
DA5 & $1.37^{*}$ & $27.31^{*}$ & $2.68^{*}$ & $53.60^{*}$ \\
WT & 2.91 & 58.22 & 3.12 & 62.48 \\
\hline
\end{tabular}

* or ** represent a significant difference between each transgenic wheat line and WT Zhoumai18 at $p<0.05$ or 0.01 (Student's $t$-test). IT represents infection type. DI represents eyespot disease index of each wheat line.

A
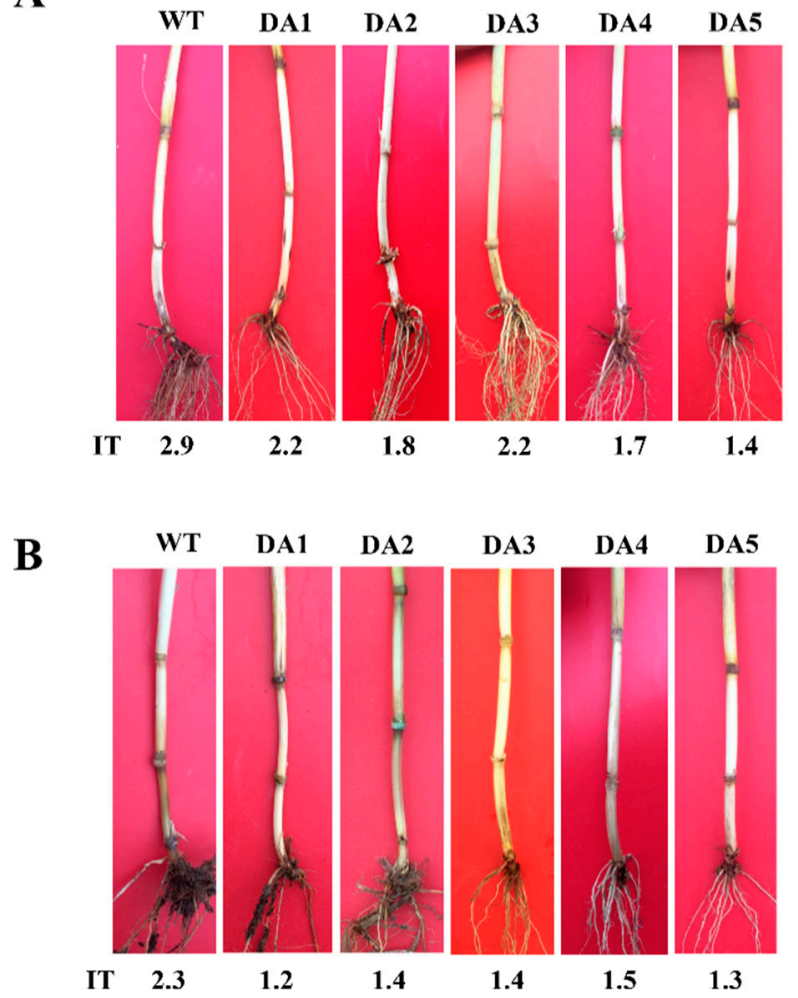

Figure 4. Typical symptoms of sharp eyespot and common root rot in DmAMP1W transgenic and non-transformed wheat plants. (A) Typical symptoms of sharp eyespot in DmAMP1W transgenic wheat lines and non-transformed wheat cv. Zhoumai18. Zhoumai18 was the transgenic recipient. DA1, DA2, DA3, DA4 and DA5 represent DmAMP1W transgenic wheat lines. IT indicates infection type. WT represents the recipient Zhoumai18. (B) Typical symptoms of common root rot in DmAMP1W transgenic wheat lines and non-transformed wheat cv. Zhoumai18. DA1, DA2, DA3, DA4 and DA5 indicate DmAMP1W transgenic wheat lines. IT represents infection type. WT represents the recipient Zhoumai18.

Moreover, the common root rot severity assessment displayed that, compared with WT Zhoumai18, these five transgenic lines (DA1, DA2, DA3, DA4 and DA5) in $\mathrm{T}_{2}$ generation exhibited significantly enhanced resistance to B. sorokiniana infection (Figure 4B); the average ITs and common root rot disease indices of these five transgenic wheat lines were 1.23-1.48 and 24.60-29.60, whereas the average IT and disease index of WT Zhoumai18 were 2.27 and 45.40, respectively (Table 2). These results suggested that expression of DmAMP1W improved resistance of the transgenic wheat plants to common root rot. 
Table 2. Responses of DmAMP1W transgenic wheat to common root rot.

\begin{tabular}{ccc}
\hline Lines & IT & DI \\
\hline DA1 & $1.44^{* *}$ & $28.80^{* *}$ \\
DA2 & $1.23^{* *}$ & $24.60^{* *}$ \\
DA3 & $1.38^{* *}$ & $27.60^{* *}$ \\
DA4 & $1.48^{* *}$ & $29.60^{* *}$ \\
DA5 & $1.33^{* *}$ & $26.60^{* *}$ \\
WT & 2.27 & 45.40 \\
\hline
\end{tabular}

** represents significant difference between each transgenic wheat line and WT Zhoumai18 at $p<0.01$ (Student's $t$-test). IT represents infection type. DI represents disease index of common root rot.

\section{Discussion}

Wheat is one of the most important staple crops globally. Wheat often is inflicted by many abiotic and biotic stresses. The pathogenic fungi $R$. cerealis and B. sorokiniana seriously reduce wheat yield in many regions of the world. It is difficult to breed wheat varieties with resistance to both diseases because of the lack of high resistance genes in wheat. It is an effective way to introduce genes with good performance to solve this problem. Broad-spectrum and stable resistance make AMPs candidates for transgenic breeding [21,36]. Our earlier works demonstrated that transgenic wheat plants expressing exogenous AMP genes exhibited increased resistance to fungal pathogens, such as Gaeumannomyces graminisvar. tritici [37], Fusarium graminearum and R. cerealis [20]. Therefore, generation of transgenic crops expressing AMPs has been an effective approach against fungal diseases [38-41]. Although Jha et al. reported that transgenic rice lines expressing DmAMP1 gene improved resistance to the diseases rice blast and rice sheath blight [26], it has not been verified that the resistance abilities of DmAMP1 to fungi diseases in wheat are real.

The correct processing, stable and efficient expression of antimicrobial peptides in transgenic plants are of great significance for the antifungal activity in plants [26]. In this study, according to wheat preference codons, we synthesized DmAMP1W gene sequence that encodes DmAMP1 mature peptide, and a signal peptide sequence was added at the $\mathrm{N}$ terminal in order to secretion of DmAMP1W. We chose DmAMP1 because of its clear disease resistance mechanism and multiple verifications that it can effectively improve plant resistance to fungal diseases [25-28]. Heterologous expression and SDS-PAGE analyses indicated that the MBP-DmAMP1W recombinant protein was highly expressed in Escherichia coli. In vitro testing demonstrated that the synthesized DmAMP1W had the expected activity and DmAMP1W inhibited effectively against mycelium growth of $R$. cerealis and B. sorokiniana. Interestingly, DmAMP1W could inhibit the fungal growth in vitro for ten days. In the transformed vector $\mathrm{pWMB122-DmAMP1W,DmAMP1W}$ was controlled by the maize ubiquitin promoter. Through Agrobacterium-mediated transformation, we generated DmAMP1W transgenic wheat lines and investigated the antifungal ability in transgenic wheat lines. DmAMP1W transgenic wheat lines exhibited enhanced-resistance to R. cerealis and B. sorokiniana compared to WT Zhoumai18, which supported our experiments in vitro. Expression of DmAMP1 in transgenic rice and papaya boosted resistance against the fungal pathogens M. oryzae, B. sorokiniana [26], and P. palmivora [25], respectively. Our results broaden the antifungal spectrum of DmAMP1 and support the conclusion of previous studies $[25,26]$. These reports proved that DmAMP1 could be used to improve resistance to fungal diseases in various transgenic plant species.

Given the great harm and cost of plant protection chemicals, researchers are more inclined to develop efficient and eco-friendly methods to control plant pathogens [26]. Generation of a broad-spectrum of disease resistant crops has always been a goal for breeders. In previous studies, Rogozhin et al. found that Ns-D2 inhibited hyphal growth of B. sorokiniana, F. oxysporum, B. cinerea and $P h$. Infestans, and its antifungal activity is similar to Rs-AFP1 and Rs-AFP2, two radish AMPs [42]. Rs-AFP2 and DmAMP1 were widely transformed into several crops, such as wheat [20], rice [13,26], maize [43] and papaya [25], and these transgenic crop plants exhibited enhanced resistance to various 
pathogens $[13,20,25,26,43]$. In this study, DmAMP1W transgenic wheat lines in $\mathrm{T}_{1}-\mathrm{T}_{2}$ generations were monitored by PCR, semi-quantitative RT-PCR and western blot assays. The results demonstrated that $D m A M P 1 W$ could be expressed in five DmAMP1W transgenic wheat lines in $\mathrm{T}_{1}-\mathrm{T}_{2}$ generations. Accordingly, disease assessment results in two consecutive years exhibited that these five DmAMP1W transgenic wheat lines, DA1, DA2, DA3, DA4 and DA5, displayed enhanced resistance to sharp eyespot in $\mathrm{T}_{1}-\mathrm{T}_{2}$ generations. In detail, sharp eyespot infection types in five transgenic lines decreased 0.69-1.54 and 0.40-0.82 compared with WT Zhoumai18, respectively. Also, expression of DmAMP1W could improve resistance of transgenic wheat to common root rot, whose common root rot infection types decreased 0.79-1.04 compared with WT Zhoumai18. The expression assay demonstrated that $D m A M P 1 W$ transcript at the adult-plant stage was widespread in the tested organs (spike, leaf, leaf sheath and stem) of the transgenic wheat and the highest expression might be in the stems. In view of $R$. cerealis and B. sorokiniana pathogens mainly attack the base stems and roots of wheat plants, and the high expression of DmAMP1W in stems is conducive to defense of transgenic wheat against infection of these pathogens. Although we tried to examine the expression of DmAMP1W in all the organs of the transgenic wheat at the adult-plant stage, unfortunately, it was difficult to extract RNA from the root for analysis in this stage. Therefore, to clarify the issue further, we need to examine $D m A M P 1 W$ expression in organs of the transgenic wheat plants at the seedling stage in the future. Taken together, the results proved that DmAMP1W peptide has resistance activity to both $R$. cerealis and B. sorokiniana in vitro and in transgenic wheat.

In conclusion, we synthesized the DmAMP1W gene according to wheat preference codons, and characterized its antifungal role in vitro and in transgenic wheat. Our results demonstrated that the synthesized DmAMP1W could correctly translate to the expected peptide. Expressing DmAMP1W peptide could inhibit mycelia growth of $R$. cerealis and B. sorokiniana in vitro. Moreover, we probed into the defensive function of $D m A M P 1 W$ in transgenic wheat against these fungal pathogen challenges, and the results demonstrated that ectopic expression of DMAMP1W increased resistance of the transgenic wheat to sharp eyespot and common root rot. In addition, DmAMP1W expression was the highest in the stems of the transgenic wheat plants, which benefited to control of the both soil-borne diseases. Our work provides new broad-spectrum antifungal accessions for wheat breeding against sharp eyespot and common root rot.

\section{Materials and Methods}

\subsection{Plant Materials and Pathogenic Fungi}

A highly-yield wheat cultivar Zhoumai 18 was used as the transformed recipient in this research. The common root rot pathogenic fungus Bipolaris sorokiniana strain ACC30209 was preserved in our laboratory. The sharp eyespot pathogenic fungus Rhizoctonia cerealis strain RC0301 was provided by Huaigu Chen and Shibin Cai in Jiangsu Academy of Agricultural Sciences, China.

\subsection{Construction of pMAL-C5X-DmAMP1W Prokaryotic Expression Vector}

The ORF sequence of DmAMP1W gene was amplified by PCR using the pMBW122-DmAMP1W plasmid as the template and with the primers (DmAMP1W-BamHI-F-: 5'-CTAGGATCCATGGTGAACAGGTCCGT-3', DmAMP1W-EcoRI-R: 5'-CACGAATTCTCAG CAGTTGAAGTAGCAGA- ${ }^{\prime}$, and the underlined stands for restriction sites to introduce BamHI and EcoRI restriction sites). Subsequently, it was subcloned into the BamHI and EcoRI sites of pMAL-C5X vector and was fused with MBP epitope tag. The recombinant vector was confirmed by sequencing and named pMAL-C5X-DmAMP1W.

\subsection{Induction, Extraction and Purification of MBP-DmAMP1W Fusion Proteins}

The pMAL-C5X-DmAMP1W and PMAL-C5X were transformed in E. coli DE3 competent cells. The transformed competent cells were grown in $200 \mathrm{~mL} \mathrm{LB}$ medium $(100 \mu \mathrm{g} / \mathrm{mL}$ ampicillin) until 
OD600 was 0.6 , and then transformed competent cells were induced with $0.1 \mathrm{mM}$ concentrations of IPTG under $28^{\circ} \mathrm{C}$ for $12 \mathrm{~h}$ at $180 \mathrm{rpm}$.

The culture was divided into $50 \mathrm{~mL}$ tubes and then centrifuged at $4000 \times g$ for $20 \mathrm{~min}$ to harvest cells. The cells were suspended in PBS buffer ( $\mathrm{pH} 7.4$ ) and divided in $1.5 \mathrm{~mL}$ tubes with $10 \mu \mathrm{L}$ lysozyme (Thermo Fisher Scientific, Boston, MA, USA). Then, the cells were broken up by freeze-thaw method. The cell debris was centrifuged for $15 \mathrm{~min}$ at $4{ }^{\circ} \mathrm{C}$ and $12,000 \times \mathrm{rpm}$. The clear supernatant, containing soluble fraction, was collected and purified; $100 \mu \mathrm{L}$ Amylose Resin (NEB, Ipswich, MA, USA) was flowed with PBS buffer ( $\mathrm{pH}$ 7.4) 3 times, and then the supernatant solution was incubated with Amylose Resin at $4{ }^{\circ} \mathrm{C}$ with end-over-end rotation overnight. The MBP and MBP-DmAMP1W were eluted by the MBP elution buffer ( $0.04 \%$ maltose solution), respectively. BCA method was used to confirm the protein concentration referring to the Easy II Protein Quantitative Kit (TransGen Biotech, Beijing, China) instruction. After that, a total of $10 \mu \mathrm{L}$ of the purified proteins were analyzed by $12 \%$ SDS-PAGE (Bio-Rad, Hercules, CA, USA).

\subsection{MBP-DmAMP1W Antifungal Activity Assay In Vitro}

The mycelial growth inhibition method [44] was used to indicate the antifungal activity of the sample with the radius of the inhibition zone. The R. cerealis and B. sorokiniana were inoculated in the center of PDA medium to culture for $2 \mathrm{~d}$ at $25^{\circ} \mathrm{C}$. After that, two symmetrical holes were punched in the medium, and MBP and MBP-DmAMP1W were injected into the hole, respectively. After the proteins infiltrated the medium, the mycelial growth was observed for 10 days.

\subsection{Generation of DmAMP1W Transgenic Wheat Plants}

$D m A M P 1 W$ was artificially synthesized according to the amino acid sequence of an antimicrobial peptide DmAMP1 isolated from dahlia. The DIAMP1W, with a His epitope tag, was subcloned into the Sam I and Sac I sites of Agrobacterium-mediated transformation vector pWMB122 [45]. In the resulting transformed vector pMBW122-DmAMP1W, the DmAMP1W-His fusion gene was driven by the maize ubiquitin (Ubi) promoter and terminated by Agrobacterium tumefaciens nopaline synthase gene (Tnos).

\subsection{DNA and RNA Extractions and cDNA Synthesis of Wheat}

For molecular analysis of transgenic wheat plants, the leaves of DmAMP1W transgenic wheat plants were collected at jointing stage to isolate DNA and RNA. Genomic DNA was extracted from the leaves using the CTAB method [46]. To analyze the tissue expression pattern of DmAMP1W in transgenic wheat lines, the transgenic wheat plants at the tillering stage were inoculated with $R$. cerealis RC0301. At 30 dpi, the roots, stem, leave, and spike were collected and deployed to RNA extraction. Total RNA was extracted using TRIzol (Invitrogen, Burlington, ON, Canada). The RNA samples were reverse-transcribed to cDNA using FastQuant RT Kit (Tiangen, Beijing, China) according to the manufacturer's instructions.

\subsection{PCR and RT-(q)PCR Analyses of DmAMP1W Transgene in Wheat}

The DmAMP1W transgenic plants was monitored by PCR using transgene-specific primers (DmAMP1W-TF: 5'-ATGAAGTTGCCGGGATTGC-3' located in the DmAMP1W coding region; DmAMP1W-TR: $5^{\prime}$-AAAACCCATCTCATAAATAACG-3' located in Tnos). The PCR reaction was set as follows: $94{ }^{\circ} \mathrm{C}$ for $3 \mathrm{~min} ; 94{ }^{\circ} \mathrm{C}$ for $30 \mathrm{~s}, 54{ }^{\circ} \mathrm{C}$ for $30 \mathrm{~s}$, and $72{ }^{\circ} \mathrm{C}$ for $2 \mathrm{~min}$, for 32 cycles; and a final extension at $72{ }^{\circ} \mathrm{C}$ for $5 \mathrm{~min}$.

Semi-quantitative RT-PCR was used to analyze the transcription of DmAMP1W in different transgenic lines. TaActin (TaActin-F: $5^{\prime}$-CACTGGAATGGTCAAGGCTG-3' and TaActin-R: $5^{\prime}$-CTCCATGTCATCCCAGTTG-3') was used as internal control. In the $25 \mu \mathrm{L}$ amplification reaction, the amounts of templates added were adjusted (Zhoumai18, 1.0 $\mu \mathrm{L}$; DA1, 0.75 $\mu \mathrm{L}$; DA2, $2.0 \mu \mathrm{L}$; DA3, $5.0 \mu \mathrm{L}$; DA4 7.0 $\mu \mathrm{L}$; DA5, $1.5 \mu \mathrm{L}$ ) according to the TaActin electrophoretic brightness in different lines. And the following materials were added: $12.5 \mu \mathrm{L}$ of $2 \times$ PCR Mixture; $0.75 \mu \mathrm{L}$ of forward and reverse 
primers (gene-specific primers for DmAMP1W were: DmAMP1W-RT-57F: 5'-TGTGCTTGCCGTTC CTCA-3' and DmAMP1W-RT-211R: $5^{\prime}$-CATCTCCGACATCGCCTC-3'), and added $\mathrm{ddH}_{2} \mathrm{O}$ to $25 \mu \mathrm{L}$. PCR went for 27 cycles and the products were examined using agarose gel electrophoresis under $120 \mathrm{~V}$ for $20 \mathrm{~min}$.

The SYBR ${ }^{\circledR}$ Premix Ex TaqTM II (TliRNaseH Plus, Takara Bio, Mountain View, CA, USA) was used to RT-qPCR assays. The ABI PRISM 7500 was used to detect according to the manufacturer's instruction (the program: $95^{\circ} \mathrm{C}$ for $30 \mathrm{~s} ; 95^{\circ} \mathrm{C}$ for $5 \mathrm{~s}, 57^{\circ} \mathrm{C}$ for $15 \mathrm{~s}$, and $72{ }^{\circ} \mathrm{C}$ for $34 \mathrm{~s}$, for 40 cycles; and a final extension at $72{ }^{\circ} \mathrm{C}$ for $10 \mathrm{~min}$ ). The relative expression level was calculated as described by Livak and Schmittgen [47].

\subsection{Western Blot Analysis on DmAMP1W Transgene Wheat}

According to the plant protein extraction kit's (CWBIO, Jiangsu, China) manufacturer's instructions, total soluble proteins were extracted from the leaves of five transgenic and WT wheat lines. In brief, $200 \mu \mathrm{g}$ of leaves each wheat line were crushed to fine powder in liquid nitrogen and resuspended in plant protein extraction reagent $(990 \mu \mathrm{L})$ with a protease inhibitor cocktail $(10 \mu \mathrm{L})$. Then, total soluble proteins were obtained by centrifugation $\left(12,000 \times g, 4^{\circ} \mathrm{C}\right)$. Total soluble proteins $(10 \mu \mathrm{L})$ from each line were heated for $10 \mathrm{~min}$ at $100{ }^{\circ} \mathrm{C}$, and the proteins were separated on $15 \%$ SDS-PAGE and transferred to PVDF membrane $(0.22 \mu \mathrm{m}$, Millipore, Boston, MA, USA).

The western blots were incubated with a 4000-fold dilution of Anti-His Mouse Monoclonal Antibody (TransGen Biotech, Beijing, China) at $4{ }^{\circ} \mathrm{C}$ and waved for $10 \mathrm{~h}$. Subsequently, using the 4000-fold dilution of secondary antibody Goat Anti-Mouse IgG (H + L, TransGen Biotech, Beijing, China), conjugated to horseradish peroxidase at $25{ }^{\circ} \mathrm{C}$ and waved for $1 \mathrm{~h}$. The DmAMP1W-His proteins were visualized using the ECL Western Blot Detection.

\subsection{Wheat Sharp Eyespot and Common Root Rot Assessments}

In $\mathrm{T}_{1}-\mathrm{T}_{2}$ generations, $D m A M P 1 \mathrm{~W}$ transgenic wheat lines and recipient Zhoumai18 were inoculated with $R$. cerealis RC0301 as described by Chen et al. [3]. The infection types (ITs, it is graded from 0 to 5) and disease index (DI) were evaluated at the harvest stage as described by Zhu et al. [48].

Following the protocol of Dong et al. [49], wheat plant response assays with B. sorokiniana were carried out. In $T_{2}$ generation, the experimental plants were planted in fields, and at the tillering stage, all the wheat plants were inoculated with B. sorokiniana. And the transgenic recipient Zhoumaii18 was used as control. Infection types (ITs, it is graded from 0 to 4 ) of wheat plants and disease index (DI) of a wheat line were evaluated at the harvest stage as described by Dong et al. [49].

Supplementary Materials: Supplementary Materials can be found at http://www.mdpi.com/1422-0067/21/2/647/s1.

Author Contributions: Z.Z. designed the experiments, supervised the work, and revised and edited the manuscript. Q.S. performed the experiments, analyzed the data and wrote the draft manuscript; K.W. transformed the gene into wheat. All authors have read and agreed to the published version of the manuscript.

Funding: This work was supported by the National "Key Sci-Tech" program of China (2016ZX08002-001-004).

Acknowledgments: Authors are grateful to Xiuliang Zhu and Xingguo Ye for help in transformation construct and generation of transgenic wheat. The study and paper are funded by the National "Key Sci-Tech" program of China (2016ZX08002-001-004).

Conflicts of Interest: The authors declare that they have no competing interests.

\section{Abbreviations}

$\begin{array}{ll}\text { AA } & \text { amino acid } \\ \text { AMP } & \text { antimicrobial peptide } \\ \text { DI } & \text { disease index } \\ \text { IPTG } & \text { isopropyl- } \beta \text {-D-thiogalactopyranoside } \\ \text { IT } & \text { infection type } \\ \text { MBP } & \text { maltose binding protein }\end{array}$


RT-qPCR reverse-transcription quantitative polymerase chain reaction

PBS phosphate buffer saline

\section{References}

1. Scofield, S.R.; Huang, L.; Brandt, A.S.; Gill, B.S. Development of a virus-induced gene-silencing system for hexaploid wheat and its use in functional analysis of the Lr21-mediated leaf rust resistance pathway. Plant Physiol. 2005, 138, 2165-2173. [CrossRef] [PubMed]

2. Hamada, M.S.; Yin, Y.; Chen, H.; Ma, Z. The escalating threat of Rhizoctonia cerealis, the causal agent of sharp eyespot in wheat. Pest Manag. Sci. 2011, 67, 1411-1419. [CrossRef] [PubMed]

3. Chen, L.; Zhang, Z.; Liang, H.; Liu, H.; Du, L.; Xu, H.; Xin, Z. Overexpression of TiERF1 enhances resistance to sharp eyespot in transgenic wheat. J. Exp. Bot. 2008, 59, 4195-4204. [CrossRef] [PubMed]

4. Zhu, X.; Lu, C.; Du, L.; Ye, X.; Liu, X.; Coules, A.; Zhang, Z. The wheat NB-LRR gene TaRCR1 is required for host defence response to the necrotrophic fungal pathogen Rhizoctonia cerealis. Plant Biotechnol. J. 2017, 15, 674-687. [CrossRef] [PubMed]

5. Lemańczyk, G.; Kwaśna, H. Effects of sharp eyespot (Rhizoctonia cerealis) on yield and grain quality of winter wheat. Eur. J. Plant Pathol. 2013, 135, 187-200. [CrossRef]

6. Wang, M.; Zhu, X.; Wang, K.; Lu, C.; Luo, M.; Shan, T.; Zhang, Z. A wheat caffeic acid 3-O-methyltransferase TaCOMT-3D positively contributes to both resistance to sharp eyespot disease and stem mechanical strength. Sci. Rep. 2018, 8, 6543. [CrossRef]

7. Wei, X.; Shan, T.; Hong, Y.; Xu, H.; Liu, X.; Zhang, Z. TaPIMP2, a pathogen-induced MYB protein in wheat, contributes to host resistance to common root rot caused by Bipolaris sorokiniana. Sci. Rep. 2017, 7, 1754. [CrossRef]

8. Kumar, J.; Schafer, P.; Huckelhoven, R.; Langen, G.; Baltruschat, H.; Stein, E.; Nagarajan, S.; Kogel, K.H. Bipolaris sorokiniana, a cereal pathogen of global concern: Cytological and molecular approaches towards better control double dagger. Mol. Plant Pathol. 2002, 3, 185-195. [CrossRef]

9. Kumar, U.; Joshi, A.K.; Kumar, S.; Chand, R.; Roder, M.S. Mapping of resistance to spot blotch disease caused by Bipolaris sorokiniana in spring wheat. Theor. Appl. Genet. 2009, 118, 783-792. [CrossRef]

10. Nawrot, R.; Barylski, J.; Nowicki, G.; Broniarczyk, J.; Buchwald, W.; Gozdzicka-Jozefiak, A. Plant antimicrobial peptides. Folia Microbiol. 2014, 59, 181-196. [CrossRef]

11. Yount, N.Y.; Yeaman, M.R. Peptide antimicrobials: Cell wall as a bacterial target. Ann. N. Y. Acad. Sci. 2013, 1277, 127-138. [CrossRef] [PubMed]

12. Parisi, K.; Shafee, T.; Quimbar, P.; van der Weerden, N.L.; Bleackley, M.R.; Anderson, M.A. The evolution, function and mechanisms of action for plant defensins. Semin. Cell Dev. Biol. 2019, 88, 107-118. [CrossRef] [PubMed]

13. Jha, S.; Chattoo, B.B. Expression of a plant defensin in rice confers resistance to fungal phytopathogens. Transgenic Res. 2010, 19, 373-384. [CrossRef] [PubMed]

14. Osborn, R.W.; De Samblanx, G.W.; Thevissen, K.; Goderis, I.; Torrekens, S.; Van Leuven, F.; Attenborough, S.; Rees, S.B.; Broekaert, W.F. Isolation and characterisation of plant defensins from seeds of Asteraceae, Fabaceae, Hippocastanaceae and Saxifragaceae. FEBS Lett. 1995, 368, 257-262. [CrossRef]

15. Tang, S.S.; Prodhan, Z.H.; Biswas, S.K.; Le, C.F.; Sekaran, S.D. Antimicrobial peptides from different plant sources: Isolation, characterisation, and purification. Phytochemistry 2018, 154, 94-105. [CrossRef]

16. Thevissen, K.; Terras, F.R.; Broekaert, W.F. Permeabilization of fungal membranes by plant defensins inhibits fungal growth. Appl. Environ. Microbiol. 1999, 65, 5451-5458. [CrossRef]

17. Thevissen, K.; Osborn, R.W.; Acland, D.P.; Broekaert, W.F. Specific binding sites for an antifungal plant defensin from Dahlia (Dahlia merckii) on fungal cells are required for antifungal activity. Mol. Plant Microbe Interact. 2000, 13, 54-61. [CrossRef]

18. Lacerda, A.F.; Vasconcelos, E.A.; Pelegrini, P.B.; Grossi, D.S.M. Antifungal defensins and their role in plant defense. Front. Microbiol. 2014, 5, 116. [CrossRef]

19. De Lucca, A.J.; Jacks, T.J.; Broekaert, W.J. Fungicidal and binding properties of three plant peptides. Mycopathologia 1998, 144, 87-91. [CrossRef] 
20. Li, Z.; Zhou, M.; Zhang, Z.; Ren, L.; Du, L.; Zhang, B.; Xu, H.; Xin, Z. Expression of a radish defensin in transgenic wheat confers increased resistance to Fusarium graminearum and Rhizoctonia cerealis. Funct. Integr. Genom. 2011, 11, 63-70. [CrossRef]

21. Sher, K.R.; Iqbal, A.; Malak, R.; Shehryar, K.; Attia, S.; Ahmed, T.; Ali, K.M.; Arif, M.; Mii, M. Plant defensins: Types, mechanism of action and prospects of genetic engineering for enhanced disease resistance in plants. 3 Biotech 2019, 9, 192. [CrossRef] [PubMed]

22. Terras, F.; Schoofs, H.; Thevissen, K.; Osborn, R.W.; Vanderleyden, J.; Cammue, B.; Broekaert, W.F. Synergistic enhancement of the antifungal activity of wheat and barley thionins by radish and oilseed rape $2 \mathrm{~S}$ albumins and by barley trypsin inhibitors. Plant Physiol. 1993, 103, 1311-1319. [CrossRef] [PubMed]

23. Almeida, M.S.; Cabral, K.S.; de Medeiros, L.N.; Valente, A.P.; Almeida, F.C.; Kurtenbach, E. cDNA cloning and heterologous expression of functional cysteine-rich antifungal protein Psd1 in the yeast Pichia pastoris. Arch. Biochem. Biophys. 2001, 395, 199-207. [CrossRef] [PubMed]

24. Spelbrink, R.G.; Dilmac, N.; Allen, A.; Smith, T.J.; Shah, D.M.; Hockerman, G.H. Differential antifungal and calcium channel-blocking activity among structurally related plant defensins. Plant Physiol. 2004, 135, 2055-2067. [CrossRef] [PubMed]

25. Zhu, Y.J.; Agbayani, R.; Moore, P.H. Ectopic expression of Dahlia merckii defensin DmAMP1 improves papaya resistance to Phytophthora palmivora by reducing pathogen vigor. Planta 2007, 226, 87-97. [CrossRef] [PubMed]

26. Jha, S.; Tank, H.G.; Prasad, B.D.; Chattoo, B.B. Expression of Dm-AMP1 in rice confers resistance to Magnaporthe oryzae and Rhizoctonia solani. Transgenic Res. 2009, 18, 59-69. [CrossRef] [PubMed]

27. Thevissen, K.; Francois, I.E.; Takemoto, J.Y.; Ferket, K.K.; Meert, E.M.; Cammue, B.P. DmAMP1, an antifungal plant defensin from dahlia (Dahlia merckii), interacts with sphingolipids from Saccharomyces cerevisiae. FEMS Microbiol. Lett. 2003, 226, 169-173. [CrossRef]

28. Im, Y.J.; Idkowiak-Baldys, J.; Thevissen, K.; Cammue, B.P.; Takemoto, J.Y. IPT1-independent sphingolipid biosynthesis and yeast inhibition by syringomycin E and plant defensin DmAMP1. FEMS Microbiol. Lett. 2003, 223, 199-203. [CrossRef]

29. Montesinos, E.; Bardaji, E. Synthetic antimicrobial peptides as agricultural pesticides for plant-disease control. Chem. Biodivers. 2008, 5, 1225-1237. [CrossRef]

30. Rajasekaran, K.; Cary, J.W.; Jaynes, J.M.; Cleveland, T.E. Disease resistance conferred by the expression of a gene encoding a synthetic peptide in transgenic cotton (Gossypium hirsutum L.) plants. Plant Biotechnol. J. 2005, 3, 545-554. [CrossRef]

31. Gaspar, Y.M.; McKenna, J.A.; McGinness, B.S.; Hinch, J.; Poon, S.; Connelly, A.A.; Anderson, M.A.; Heath, R.L. Field resistance to Fusarium oxysporum and Verticillium dahliae in transgenic cotton expressing the plant defensin NaD1. J. Exp. Bot. 2014, 65, 1541-1550. [CrossRef] [PubMed]

32. Patkar, R.N.; Chattoo, B.B. Transgenic Indica rice expressing ns-LTP-Like protein shows enhanced resistance to both fungal and bacterial pathogens. Mol. Breed. 2006, 17, 159-171. [CrossRef]

33. Roy-Barman, S.; Sautter, C.; Chattoo, B.B. Expression of the lipid transfer protein Ace-AMP 1 in transgenic wheat enhances antifungal activity and defense responses. Transgenic Res. 2006, 15, 435-446. [CrossRef] [PubMed]

34. Thevissen, K.; Cammue, B.P.; Lemaire, K.; Winderickx, J.; Dickson, R.C.; Lester, R.L.; Ferket, K.K.; Van Even, F.; Parret, A.H.; Broekaert, W.F. A gene encoding a sphingolipid biosynthesis enzyme determines the sensitivity of Saccharomyces cerevisiae to an antifungal plant defensin from dahlia (Dahlia merckii). Proc. Natl. Acad. Sci. USA 2000, 97, 9531-9536. [CrossRef] [PubMed]

35. Yang, K.; Liu, X.; Du, L.P.; Ye, X.G.; Zhang, Z.Y. Development and characterization of AcAMP-sn transgenic wheat with enhanced resistance to wheat take-all. Acta Agron. Sin. 2014, 40, 22. (In Chinese) [CrossRef]

36. Almasia, N.I.; Bazzini, A.A.; Hopp, H.E.; Vazquez-Rovere, C. Overexpression of snakin-1 gene enhances resistance to Rhizoctonia solani and Erwinia carotovora in transgenic potato plants. Mol. Plant Pathol. 2008, 9, 329-338. [CrossRef]

37. Rong, W.; Qi, L.; Wang, J.; Du, L.; Xu, H.; Wang, A.; Zhang, Z. Expression of a potato antimicrobial peptide $\mathrm{SN}_{1}$ increases resistance to take-all pathogen Gaeumannomyces graminis var. tritici in transgenic wheat. Funct. Integr. Genom. 2013, 13, 403-409. [CrossRef]

38. Breen, S.; Solomon, P.S.; Bedon, F.; Vincent, D. Surveying the potential of secreted antimicrobial peptides to enhance plant disease resistance. Front. Plant Sci. 2015, 6, 900. [CrossRef] 
39. Ali, S.; Ganai, B.A.; Kamili, A.N.; Bhat, A.A.; Mir, Z.A.; Bhat, J.A.; Tyagi, A.; Islam, S.T.; Mushtaq, M.; Yadav, P.; et al. Pathogenesis-related proteins and peptides as promising tools for engineering plants with multiple stress tolerance. Microbiol. Res. 2018, 212-213, 29-37. [CrossRef]

40. Silva, M.S.; Arraes, F.; Campos, M.A.; Grossi-de-Sa, M.; Fernandez, D.; Candido, E.S.; Cardoso, M.H.; Franco, O.L.; Grossi-de-Sa, M.F. Review: Potential biotechnological assets related to plant immunity modulation applicable in engineering disease-resistant crops. Plant Sci. 2018, 270, 72-84. [CrossRef]

41. Das, K.; Datta, K.; Karmakar, S.; Datta, S.K. Antimicrobial peptides-small but mighty weapons for plants to fight phytopathogens. Protein Pept. Lett. 2019, 26, 720-742. [CrossRef] [PubMed]

42. Rogozhin, E.A.; Oshchepkova, Y.I.; Odintsova, T.I.; Khadeeva, N.V.; Veshkurova, O.N.; Egorov, T.A.; Grishin, E.V.; Salikhov, S.I. Novel antifungal defensins from Nigella sativa L. seeds. Plant Physiol. Biochem. 2011, 49, 131-137. [CrossRef] [PubMed]

43. Zhu, X.; Zhao, J.; Abbas, H.; Liu, Y.; Cheng, M.; Huang, J.; Cheng, W.; Wang, B.; Bai, C.; Wang, G.; et al. Pyramiding of nine transgenes in maize generates high-level resistance against necrotrophic maize pathogens. Theor. Appl. Genet. 2018, 131, 2145-2156. [CrossRef] [PubMed]

44. Liu, B.; Lu, Y.; Xin, Z.; Zhang, Z. Identification and antifungal assay of a wheat $\beta$-1,3-glucanase. Biotechnol. Lett. 2009, 31, 1005-1010. [CrossRef] [PubMed]

45. Wang, K.; Liu, H.; Du, L.; Ye, X. Generation of marker-free transgenic hexaploid wheat via an Agrobacterium-mediated co-transformation strategy in commercial Chinese wheat varieties. Plant Biotechnol. J. 2017, 15, 614-623. [CrossRef] [PubMed]

46. Saghai-Maroof, M.A.; Soliman, K.M.; Jorgensen, R.A.; Allard, R.W. Ribosomal DNA spacer-length polymorphisms in barley: Mendelian inheritance, chromosomal location, and population dynamics. Proc. Natl. Acad. Sci. USA 1984, 81, 8014-8018. [CrossRef]

47. Livak, K.J.; Schmittgen, T.D. Analysis of relative gene expression data using real-time quantitative PCR and the $2^{-\Delta \Delta C t}$ method. Methods 2001, 25, 402-408. [CrossRef]

48. Zhu, X.; Yang, K.; Wei, X.; Zhang, Q.; Rong, W.; Du, L.; Ye, X.; Qi, L.; Zhang, Z. The wheat AGC kinase TaAGC1 is a positive contributor to host resistance to the necrotrophic pathogen Rhizoctonia cerealis. J. Exp. Bot. 2015, 66, 6591-6603. [CrossRef]

49. Dong, N.; Liu, X.; Lu, Y.; Du, L.; Xu, H.; Liu, H.; Xin, Z.; Zhang, Z. Overexpression of TaPIEP1, a pathogen-induced ERF gene of wheat, confers host-enhanced resistance to fungal pathogen Bipolaris sorokiniana. Funct. Integr. Genom. 2010, 10, 215-226. [CrossRef] 